\title{
The Influence of Age and Sex on Casual Blood Pressure Levels among Jatapu Tribals of Srikakulam District of Andhra Pradesh
}

\author{
M. Gopi Chand and R.S. Rao \\ Department of Anthropology, Andhra University, Visakhapatnam 530 003, \\ Andhra Pradesh, India \\ Telephone: 0891-2844233, E-mail: gopichandmp@yahoo.com
}

KEYWORDS Rising of Blood Pressure. Urbanization. Physiological Changes

ABSTRACT The influence of age and sex on blood pressure levels was studied in Jatapu population of Srikakulam district, Andhra Pradesh. The occupational mobility and the acculturation in this community might have brought some changes in their blood pressure. The present Jatapu population shows a positive relationship between age, sex and blood pressure, like some of the neighboring tribal populations of Eastern Ghats region of Andhra Pradesh.

\section{INTRODUCTION}

The change in arterial blood pressure is one of the generally known physiological changes in aging of man. A continues increase in blood pressure levels during adulthood is one of the major health concern in almost all the modern societies. Many factors are responsible for the rise of blood pressure, of which age is one of the main responsible factor; because in the process of aging the structural, functional, and biochemical changes occur with the influence of various genetic and environmental factors. The studies highlighting the relationship between age, sex and blood pressure are in good manner (Padmavathi,1959; Gupta, 1979; Sambasiva Rao, 1979, 1980). The earlier studies (Donnison, 1929; Lowenstein, 1961; Maddocks, 1961; Trusewell et al., 1972) on some of the tribal communities of the world revealed that there was little or no increase in adult blood pressure. However some of the tribal population groups which migrate to urbanized areas or undergo modernization or change in their occupation in situ have shown tendencies towards an increase in blood pressure with ageing (Scotch, 1963; Cruz-Coke et al., 1964; Prior, 1970). But, the studies in similar line on tribal population from Indian context are few (Mukhopadhyay et al., 1996; Kusuma et al., 2001). The present study investigates the influence of age and sex on blood pressure of Jatapu tribal community of Srikakulam District in Andhra Pradesh.

\section{MATERIALS AND METHODS}

During February 2002, a total of 308 Subjects
(159 men and 149 women) were selected randomly from the adult population (15 Years and above age) of Jatapu tribe, habituating the North costal District Srikakulam of Andhra Pradesh, South India. Casual blood pressures were measured with a mercury sphygmomanometer at domiciliary condition after the subject was kept under ease, in the sitting posture, between 7.00 am and noon. Three consecutive readings were taken for both systolic and diastolic blood pressure and the average was considered as the pressure level of the participant. Most of the tribal people were illiterates and not having any written age proof, so the investigator to the best of his approximation assessed the age.

\section{RESULTS}

The means and corresponding standard deviations and ' $\mathrm{t}$ ' values for systolic and diastolic blood pressure by age and sex groups presented in Table 1. It can be inferred that the present study population is not showing any consistency in the increase of blood pressure levels on the age advances, and ' $t$ ' values also shown that there is no significant sex difference. In order to evaluate the influence of age on blood pressure the mean values are calculated by combining the inversion point as 45 years, and the study population divided in to younger ( 15 to 45 years) and older (45 e" years) age groups. The means, standard deviations and ' $t$ ' values of both systolic and diastolic blood pressures among younger and older age groups are show in Table 2. It is discernable from this table, that the older age group having higher mean blood pressure levels in both systolic and diastolic, than the younger 
Table 1: Means and standard deviation of systolic and diastolic blood pressure among various age groups of men and women of Jatapu tribal population.

\begin{tabular}{|c|c|c|c|c|c|c|c|}
\hline \multirow{2}{*}{$\begin{array}{l}\text { Age Group } \\
\text { (in years) }\end{array}$} & \multicolumn{3}{|c|}{ Men } & \multicolumn{3}{|c|}{ Women } & \multirow[t]{2}{*}{ ' $t$ ' Value } \\
\hline & Number & Mean & $\pm S . D$ & Number & Mean & $\pm S . D$ & \\
\hline \multicolumn{8}{|c|}{ Systolic Blood Pressure } \\
\hline $15-24$ & 29 & 121.62 & 3.05 & 29 & 119.86 & 4.29 & 1.799 \\
\hline $25-34$ & 38 & 121.53 & 3.92 & 27 & 120.63 & 6.65 & 0.682 \\
\hline $35-44$ & 28 & 123.46 & 10.35 & 30 & 122.93 & 5.60 & 0.245 \\
\hline $45-54$ & 27 & 123.26 & 3.88 & 27 & 127.26 & 13.54 & 1.476 \\
\hline $55-64$ & 31 & 126.03 & 4.67 & 29 & 127.00 & 7.55 & 0.601 \\
\hline $65>$ & 06 & 128.33 & 3.33 & 07 & 130.14 & 6.52 & 0.612 \\
\hline \multicolumn{8}{|c|}{ Diastolic Blood Pressure } \\
\hline $15-24$ & 29 & 81.00 & 2.60 & 29 & 81.93 & 2.83 & 1.304 \\
\hline $25-34$ & 38 & 82.00 & 4.33 & 27 & 80.78 & 4.13 & 1.143 \\
\hline $35-44$ & 28 & 81.89 & 3.30 & 30 & 81.67 & 4.85 & 0.206 \\
\hline $45-54$ & 27 & 82.37 & 3.03 & 27 & 85.78 & 4.89 & $3.007 *$ \\
\hline $55-64$ & 31 & 83.90 & 4.47 & 29 & 85.76 & 4.15 & 1.663 \\
\hline $65>$ & 06 & 84.67 & 5.16 & 07 & 82.29 & 6.75 & 0.704 \\
\hline
\end{tabular}

* Significant at $5 \%$ level.

Table 2: Means and standard deviations of systolic and diastolic blood pressure among young (15 - 44 years) and old (45>) age groups.

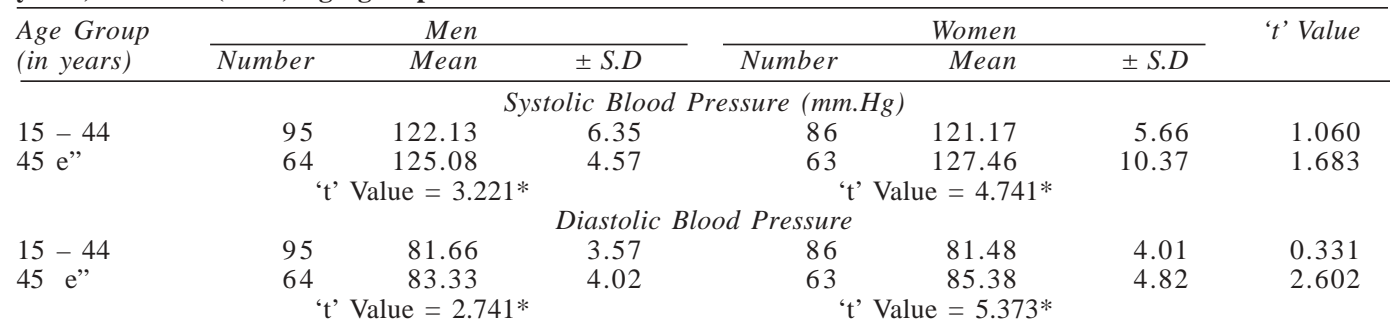

* Significant at $5 \%$ level.

age group in both the sexes. But the sex difference not statistically significant.

In order to know the influence of age on blood pressure levels, the single regression analysis is used. It is apparent from the Table 3 , it is clear that both systolic and diastolic blood pressures are statistically significant on age among both the men and women. From table 3 it is clear that both systolic and diastolic starts to rise in more among men $(118 / 79.44 \mathrm{mmHg})$ than the women (115.19/ $78.8 \mathrm{mmHg}$ ). The rate at which the systolic starts to rise for given unit of age is 1.33 $\mathrm{mmHg}$ among men and $1.08 \mathrm{mmHg}$ among women per year. It is clearly evident from the regression analysis that the rise of both systolic as well as diastolic is more among women, even though the constants are relatively lesser than man.

Distribution of blood pressure levels as per the recommendations of U.S. Joint National Committee for detection, evaluation, and treatment of high blood pressure (JNC V) classification is shown in table 4. It can be inferred that the majority of men and women fall under normal range, i.e. $74.2 \%$ men and $59.7 \%$ women were fall under normal systolic range (120-129 $\mathrm{mmHg}$ ) and $67.3 \%$ men and $50.3 \%$ women fall under normal diastolic range $(80-84 \mathrm{mmHg}) .17 \%$ of men and $23.5 \%$ women were fall under optimal

Table 3: Liner regression coefficients of age on systolic and diastolic blood pressure levels in men and women of Jatapu Tribals.

\begin{tabular}{llrrrrrr}
\hline Sex & B.P & Constant & Reg. Coeff & S.E & 't' Value & R. Square & \multicolumn{1}{c}{$F$} \\
\hline \multirow{2}{*}{ Men } & SBP & 118.03 & $0.133^{*}$ & 0.03. & 4.427 & $0.111^{*}$ & 19.60 \\
\multirow{3}{*}{ Women } & DBP & 79.44 & $0.073^{*}$ & 0.02. & 3.625 & $0.077^{*}$ & 13.09 \\
& SBP & 115.19 & $0.215^{*}$ & 0.045 & 4.832 & $0.137^{*}$ & 23.35 \\
& DBP & 78.80 & $0.108^{*}$ & 0.025 & 4.275 & $0.111^{*}$ & 18.28 \\
\hline
\end{tabular}

* Significant at $5 \%$ level. 
range of systolic and $13.2 \%$ men and $16.1 \%$ women were fall under optimal range of diastolic blood pressure. Nearly $11 \%$ of women and $2.5 \%$ of men are fall under first stage of hypertension. Very few people are having high blood pressure levels under stage two and three respectively.

\section{DISCUSSION}

Relatively high level of blood pressure among older groups than in the younger groups of present study conforms that the well established phenomenon of high blood pressure and increased blood pressure levels with age accompany the process of modernization (Scotch, 1963).

The present study population results are comparable to other tribal population studies of Andhra Pradesh as shown in Table 5. With respect to this, age shows significantly positive effect on the rise of blood pressure in the present study, like the studies conducted on Konda Doras (Jaya Laxmi, 1989), Mali (Naidu, 1991) Chenchu (Murthy Ramana, 1992) and Valmiki (Srinivas, 1997). As well as age show more impact on the rise of the systolic blood pressure rather than the diastolic blood pressure in both men and women of the present study, similar trends holds good in the case of Konda Doras, Chenmchus and Valmiki. Among high and low altitude populations from Central Asia, that age explained $1 \%$ and $3 \%$ of Systolic blood pressure $(\mathrm{P}<0.05)$ and Diastolic Blood Pressure $(\mathrm{P}<0.05)$ variance respectively (Facchini et al., 2000). Among Lepchas of Sikkim, Himalayas reported that age has significant effect on both systolic blood pressure and diastolic blood pressure in both sexes (Mukhopadhayay et al., 1996). In a rural population, that blood pressure increases significantly along with advancing age (Joshi et al., 1993). Finally it may be inferred that systolic rather than diastolic blood pressure is relatively more sensitive to the effect of age. During the process of aging other structural, functional and biological changes takes place in human beings and they have attracted considerable attention in man's efforts to postpone ageing and increase the longevity. Thus the change in blood pressure is one of the commonly known physiological changes in aging of man.

In the present population both the blood pressure levels of men and women are greatly influenced by age factor. Further it is also observed that age has more influence on systolic blood pressure rather than diastolic blood pressure, unlike the studies conducted on Kondh (Mahalakshmi, 2001), Savaras ( Rajesh, 2002), Bagatas (Kumar, 1996) and Nooka Doras (Prasanna Rani, 1994) tribes of Andhra Pradesh. Majority of the earlier studies revealed that blood pressure increases with advancing of age and is tempered by other features like sex, socio economic circumstances etc. (Padmavathi, 1959; Mathus, 1970; Gupta, 1979; Sambasiva Rao, 1979, 1980). Where as some of the studies conducted on the so-called primitive communi-ties of Africa, Asia and Polynesian islands (Lowenstein, 1961; Maddocks, 1961; Boe, 1978) revealed that age has no bearing on blood pressure.

The present population exhibits the relation ship between age and blood pressure, this trend is may be because of the change in Jatapu's socio-

Table 4: Distribution of blood pressure levels among Jatapu as per JNC - V classification.

\begin{tabular}{|c|c|c|c|c|c|c|}
\hline \multirow[t]{2}{*}{ Blood Pressure } & & \multirow[t]{2}{*}{ Range (mm.Hg) } & \multicolumn{2}{|c|}{ Men } & \multicolumn{2}{|c|}{ Women } \\
\hline & & & Number & Percentage & Number & Percentage \\
\hline \multirow{2}{*}{ Optimal : } & SBP & $<120$ & 27 & 17.0 & 35 & 23.5 \\
\hline & DBP & $<80$ & 21 & 13.2 & 24 & 16.1 \\
\hline Normal : & SBP & $120-129$ & 118 & 74.2 & 89 & 59.7 \\
\hline DBP & & $80-84$ & 107 & 67.3 & 75 & 50.3 \\
\hline \multirow[t]{2}{*}{ High Normal: } & SBP & $130-139$ & 13 & 8.2 & 21 & 14.1 \\
\hline & DBP & $85-89$ & 26 & 16.04 & 34 & 22.8 \\
\hline \multicolumn{7}{|l|}{ Hypertension } \\
\hline \multirow[t]{2}{*}{ Stage -1} & SBP & $140-159$ & - & - & 3 & 2.0 \\
\hline & DBP & $90-99$ & 4 & 2.5 & 16 & 10.7 \\
\hline \multirow[t]{2}{*}{ Stage -2} & SBP & $160-179$ & 1 & 0.6 & - & - \\
\hline & DBP & $100-109$ & 1 & 0.6 & - & - \\
\hline \multirow[t]{2}{*}{ Stage -3} & SBP & $180-209$ & - & - & 1 & 0.7 \\
\hline & DBP & $110-119$ & - & - & - & - \\
\hline \multirow[t]{2}{*}{ Stage -4} & SBP & $>210$ & - & - & - & - \\
\hline & $\mathrm{DBP}$ & $>120$ & - & - & - & - \\
\hline
\end{tabular}




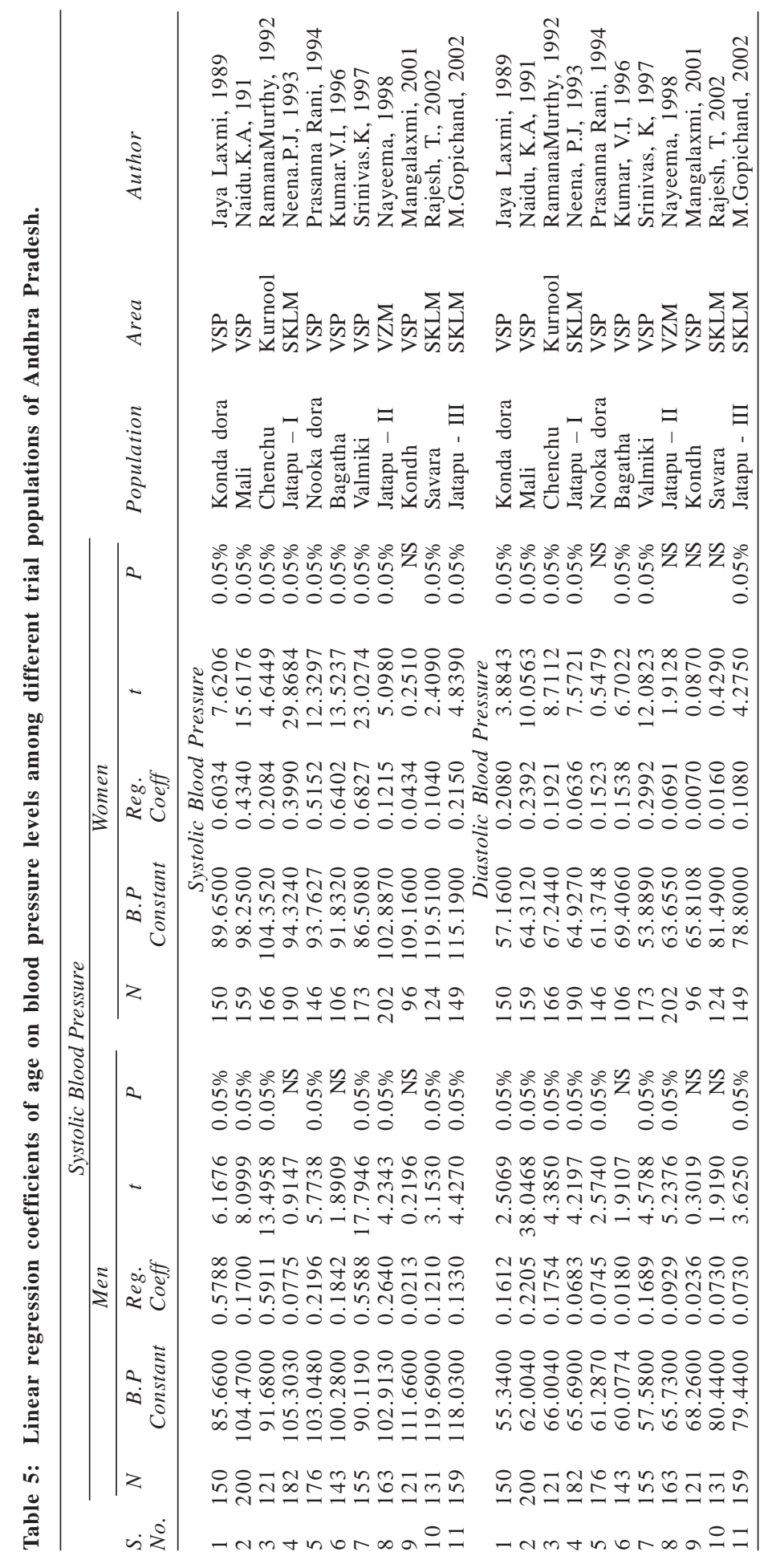


economic and other environmental factors. The present study population Jatapu, when compared with the Savaras and Kondhs of this region, are relatively developed in many spheres. Though the primary occupation of the tribes inhibiting at Eastern Ghats is food gathering and hunting, the Jatapus like Koyadora, Bagatas and Valmiki, heve developed settled agriculture. Majority of the people in the present study population were growing crops like Cashew, Turmeric, Mango, and Paddy, this trend relatively leads them to financially sound situation. Due to the development of agriculture, the Jatapus are habituated to visit the near by Mandal Head Quarter to sell their agricultural and forest produce in the markets and shandies. In this context they have the opportunity to deal with the caste people of plain areas and at the same time, they are more exposed to the urban environment. This situation leads to many changes in their thinking process, dress pattern, food habits, recreation etc. It is also observed in the present study, the people residing in the road side villages are availing the buses and other transport facilities and at the same time changes were found in their physical activity. Thus the rise of the blood pressure in this community with advancing age has been variously linked with different wings of civilization and modernization is permits us to formulate the assumption, that the environmental conditions under which present population lives are responsible for the variation in blood pressure. Similar trend holds good even in the case of other tribal populations, which are show-ing rise of blood pressure with the advancement of age.

The problem of CVD in the developing countries is generally perceived to affect only the rich. However it is clear that the evolving epidemics of CVD affect the health of poor both directly and indirectly (Howson et al., 1998). The present study along with some earlier studies from different parts of Andhra Pradesh reveals that the epidemic of high blood pressure is passing through various sections of people, including the low socio-economic strata of society.

\section{REFERENCES}

Boe, J.: The blood pressure in a population. Acta Medica Scandinavica, 157: 321 and 326 (1978).

Cruz-Coke, R.: Influence of migration on blood pressure in Easter Islanders. Lancet, II: 697-699 (1964).

Donnision, C.P.: Blood pressure in the African native. Lancet, I: 6 (1929).
Facchini, G.F. Fiori, Rimondi, D. Pettener, Battistini, N. and Bedogni, G.: Relationships between blood pressure, anthropometric characteristics and blood lipids in high and low altitude populations from Central Asia. Annals of Human Biology, 27: 19-28 (2000)

Gopi Chand, M.: Influence of Age, Sex, Body Weight and Other Bio Anthropological Factors on the Rise of Blood Pressure. Unpublished M.Sc. dissertation, Andhra University, Visakhapatnam (2002).

Gupta, V.R.: Hypertension and Blood pressure trends in the general population of Haryana (Based on total community surveys). Journal of Association of Physicians of India, 27: 119-126 (1979).

Howson, C.P., Reddy, K.S., Rayan, T.J. and Bale, R.B.: Control of Cardiovascular Diseases in Developing Countries, Research, Developing and International Strengthening. Report of Committee on Research Development and International strengthening for Control of Cardiovascular Disease in Developing countries. Washington DC : National Academic Press, (1998)

Jayalakshmi, M.: Blood Pressure Levels of Konda Dora's with Special Reference to Age, Sex, and Body Weight. Unpublished M.Sc. dissertation, Andhra University, Visakhapatnam (1989).

Joshi, P.P., Kate, S.K. and Shegokar, V.: Blood Pressure trends and life style risk factors in rural India. Journal of Association of Physicians India, 41: 579-581 (1993).

Kumar, V.I.: Influence of Age, Sex Body Weight and Other Bio-anthropological Factors on the Rise of Blood Pressure - A Study Among Bagatas. Unpublished M.Sc dissertation, Andhra University, Visakhapatnam (1996).

Kusama, Y.S.: Group and sex - specific effects of age, body composition and pulse rate on blood pressure variability in some cross cultural populations of Visakhapatnam District, South India. Journal of Cardiovascular Risk, 8: 337-347 (2001).

Lowenstein, F.W.: Blood pressure in relation to age and sex in the tropic and sub tropics. Lancet, I: 389-392 (1961).

Maddocks, I.: The Influence of standard living in blood pressure. Fiji. Circulation, 24: 1220-1223 (1961).

Mangalakshmi, P.: Influence of Age, Sex, Body Weight and Other Bio-anthropological Factors on the Rise of Blood Pressure among Kondh's of Visakhapatnam Distrisct, Andhra Pradesh. Unpublished M.Sc dissertation, Andhra University, Visakhapatnam (2001).

Mukhopadhayay, B.:Blood pressure profile of Lepchas of the Sikkim Himalayas, epidemiological study. Human Biology, 68: 131-145 (1996).

Murthy, Ramana: Blood Pressure in Chenchu Tribals of Prakasam and Kurnool District. Unpublished M.Sc. dissertation, Andhra University, Visakhapatnam (1992).

Naidu,K.A.: Blood Pressure in Mali Tribals of Visakhapatnam District. Unpublished M.Sc. dissertation, Andhra University, Visakhapatnam (1991).

Nayeema: Influence of Age, Sex, Body Weight and Other Bio-anthropological Factors on the Rise of Blood Pressure among Jatupu of Vizinigaram District, Andhra Pradesh. Unpublished M.Sc. Dissertation, Andhra University, Visakhapatnam (1998). 
Neena, P.J.: Blood Pressure Trends Among Jatapu Tribals. Unpublished M.Sc. dissertationm, Andhra University, Visakhapatnam (1993).

Padmavati,S.: Blood pressure studies in urban and rura groups of Delhi. Circulation 19: 395 (1959).

Prassanna Rani, P.D.: Blood Pressure Study Among Nooka Dora Tribals. Unpublished M.Sc dissertation, Andhra University, Visakhapatnam (1994).

Prior, I.A.M.: Sodium in take and blood pressure in two Polynesian populations. New England Journal of Medicine, 279: 515 (1970).

Rajesh, T.: Blood Pressure Among Savara Tribals. Unpublished M.Sc. Dissertation, Andhra University, Visakhapatnam, (2002).

Sambasiva Rao, R.: Blood presuure in relation to age and sex in a rural population. Man in India, 59: 97-105 (1979).

Sambasiva Rao, R.: Blood pressure in relation to age and sex in a semi-urban population. Annals of Human biology, 7: 277-280 (1980).

Scotch, N.A.: Socio-Cultural factors in the epidemiology of Zulu Hypertension. American Journal of Public Health, 53: 1205 (1963).

Srinivas, K.: Variation Blood Pressure with Age, Sex, Arm and Abdominal Girth Among Valmiki Tribals. Unpublished M.Sc. Dissertation, Andhra University, Visakhapatnam (1997).

Trusewell, A.S.: Blood pressure of Kung Bushmen in Northern Botswana. American Heart Journal, 1: 512 (1972). 